\title{
Os Conselhos Municipais de Educação no âmbito do planejamento decenal estadual da educação2014-2024 no Brasil ${ }^{1}$
}

\author{
Rosimar de Fátima Oliveira ${ }^{2}$ \\ Donaldo Bello de Souza ${ }^{3}$
}

Resumo: O presente artigo visa ao exame de como os Conselhos Municipais de Educação (CMEs) são tratados no âmbito do planejamento estadual da educação, tomando por base empírica os Planos Estaduais de Educação relativos ao Plano Nacional de Educação 2014-2024, que tenham sido efetivamente transformados em norma jurídica até o mês de dezembro de 2016. As análises evidenciam a existência, por um lado, de uma intensa repercussão nesses documentos da responsabilização atribuída pelo PNE 2014-2024 aos poderes executivos estaduais e municipais pelo funcionamento e autonomização dos CMEs, e, por outro, de uma forte atribuição de competências articuladas aos processos participativos e à fiscalização.

Palavras-chave: conselhos municipais de educação, planos estaduais de educação, plano nacional de educação, gestão democrática da educação

\section{The Municipal Education Councils in the framework of the state educational decennial planning (2014-2024) in Brazil}

Abstract: This article aims at examining how the Municipal Education Councils (CMEs) are treated in the scope of state education planning, taking as empirical basis the State Education Plans related to the National Education Plan (2014-2024), which have been effectively transformed into legal norm up to the month of December 2016. The analyses highlight the

\footnotetext{
${ }^{1}$ Artigo associado à pesquisa intitulada "Estudo crítico-exploratório sobre os Planos Estaduais de Educação (PEEs) no Brasil: contribuições para formulações e reformulações decorrentes do novo Plano Nacional de Educação (PNE)", levado a efeito pelo Núcleo de Estudos em Política e História da Educação Municipal (NEPHEM) da Faculdade de Educação da Universidade do Estado do Rio de Janeiro (UERJ), pelo Grupo de Pesquisa Política e Administração de Sistemas de Ensino (GruPase) da Faculdade de Educação da Universidade de Minas Gerais (UFMG) e pelo Núcleo de Estudos Tempos, Espaços e Educação Integral (NEEPHI) da Faculdade de Educação da Universidade Federal do Estado do Rio de Janeiro (UNIRIO).

${ }^{2}$ Professora Adjunta no Programa de Pós-Graduação Conhecimento e Inclusão Social da Universidade Federal de Minas Gerais (UFMG). Doutora em Educação pela Universidade de São Paulo (USP).E-mail: rosimarfoliveira@gmail.com.

${ }^{3}$ Professor Associado na Faculdade de Educação da Universidade do Estado do Rio de Janeiro (UERJ). Pós-doutor em Política e Administração Educacional pela Faculdade de Psicologia e de Ciências da Educação da Universidade de Lisboa (FPCE /UL). E-mail: donaldobello@gmail.com.
}

\begin{tabular}{|l|l|l|l|l|} 
Textura & Canoas & v. 19 n.40 & p.116-138 & maio/ago. 2017 \\
\hline
\end{tabular}


existence, on one hand, of intense repercussion in these documents of the accountability attributed by the PNE (2014-2024) to the state and municipal executive powers for the functioning and autonomization of the CMEs, and, on the other hand, of a strong attribution of competences linked to the participatory processes and to the inspection.

Keywords: Municipal Education Councils; State Education Plans; National Education Plan; Democratic management of education.

\section{INTRODUÇÃO}

Em 2013, foi publicada a coletânea intitulada "Mapa dos Conselhos Municipais de Educação no Brasil" (SOUZA, 2013a), que trouxe à vista o exame sobre o funcionamento institucional e sociopolítico destes órgãos colegiados, em âmbito nacional. Consiste em um estudo que tomou por base levantamento documental exaustivo em torno da produção teórico-empírica relativa a esses órgãos colegiados, publicada no Brasil no período 1996-2010, tendo operado com os resultados de investigações sobre 291 Conselhos Municipais de Educação (CMEs) pertencentes a $12 \operatorname{estados}^{4}$ e ao Distrito Federal, englobando 6,6\% dos 4.403 desses órgãos existentes, em 2009, no País (SOUZA, 2013b).

A apreciação global dos resultados das investigações acima aludidas veio a revelar diversos problemas estruturais e conjunturais comuns entre os CMEs enfocados, relativos tanto à sua criação e implantação, quanto ao funcionamento institucional e sociopolítico. Tais problemas são apontados por Souza, Duarte e Oliveira (2013, p. 48) como decorrentes da "ausência de um projeto político de Estado (ao nível federal, estadual e local) voltado para a autonomização dos CMEs", o que tornaria essas instâncias "reféns das políticas de governo, comprometendo, por conseguinte, o ideário da gestão democrática da Educação Básica [...]" (SOUZA; DUARTE; OLIVEIRA, 2013, p. 48).

${ }^{4}$ Bahia, Espírito Santo, Mato Grosso do Sul, Minas Gerais, Pará, Paraíba, Paraná, Pernambuco, Rio de Janeiro, Rio Grande do Sul, Santa Catarina e São Paulo (SOUZA, 2013b). 
Uma das possibilidades de legalmente se assegurar uma política de Estado $^{5}$ que favoreça, na esfera nacional, a consolidação dos CMEs no País consiste na sua inclusão como instância de gestão democrática em metas/objetivos de instrumentos de planejamento da área, como os Planos de Educação.No âmbito do Plano Nacional de Educação (PNE) 2001-2010 -Lei $\mathrm{n}^{\mathrm{o}}$ 10.172, de 09 de janeiro de 2001(BRASIL, 2001) -, o CME será explicitamente evocado no eixo temático sobre o Financiamento, determinando que se estimulasse sua criação, assim como tecnicamente apoiasse os municípios que viessem a optar "por constituir sistemas municipais de ensino"(BRASIL, 2001, Eixo V, Objetivo/Meta 21).

Mais recentemente, com a aprovação do PNE 2010-2014 - Lei $\mathrm{n}^{\circ}$ 13.005, de 25 de junho de 2014 (BRASIL, 2014) - os CMEs, ao lado dos Conselhos Escolares (CEs), vieram a ser incluídos neste instrumento de gestão, num primeiro momento reiterando o estímulo à sua constituição e fortalecimento (perspectiva igualmente constate do PNE 2001-2010), mas, em seguida, dando ênfase ao papel a ser desempenhado nos sistemas locais de ensino, nos termos de sua configuração "como instrumentos de participação e fiscalização na gestão escolar e educacional, inclusive por meio de programas de formação de conselheiros, assegurando-se condições de funcionamento autônomo" (BRASIL, 2014, Meta 19, Estratégia 21).

No plano infranacional, é possível afirmar que são pouquíssimos os trabalhos que tratam do exame dos Conselhos de Educação em instrumentos de planejamento como os Planos Municipais de Educação (PMEs) e os Planos Estaduais de Educação (PEEs). No primeiro caso, estudo de Souza \& Alcântara (2016), enfocando os PMEs da Região Metropolitana do Rio de Janeiro (RM-RJ) alinhados ao PNE 2001-2010, tematizao papel desses órgãos na discussão, elaboração acompanhamento e avaliação dos planos correlatos, constatando que, não obstante o fato de os planos objetivados terem destacado a participação da sociedade civil na sua construção, os CMEs, em geral, não tiveram um lugar de destaque na gestão democrática da educação local. No segundo caso, distingue-se, por exemplo, o estudo de Souza \& Menezes

5 "Considera-se que políticas de governo são aquelas que o Executivo decide num processo elementar de formulação e implementação de determinadas medidas e programas, visando responder às demandas da agenda política interna, ainda que envolvam escolhas complexas. Já as políticas de Estado são aquelas que envolvem mais de uma agência do Estado, passando em geral pelo Parlamento ou por instâncias diversas de discussão, resultando em mudanças de outras normas ou disposições preexistentes, com incidência em setores mais amplos da sociedade" (OLIVEIRA, 2011, p. 329). 
(2015) que, apesar de não ter tomando por questão central os Conselhos de Educação, postula que, no âmbito dos PEEs, também consoantes ao PNE 2001-2010, não se verifica a configuração do Conselho Estadual de Educação (CEE) como lócus privilegiado para a coordenação e/ou construção desse plano. Em trabalho mais recente, ainda não publicado, Oliveira, Souza \& Câmara (2016), igualmente com foco nos PEEs, mas agora coesos ao PNE 2014-2024, identifica aspectos relativos à ausência de protagonismo do CEE na elaboração do PEE, ao esvaziamento de sua competência como órgão dos Sistemas Estaduais de Ensino e, ainda, à fragilidade referente ao aporte desse mesmo sistema para a sua infraestrutura.

Dado ao número extremamente reduzido de estudos em questão, assim como a sua incipiência, no presente artigo procede-se ao exame de como os CMEs são tratados no âmbito do planejamento estadual da educação, tomando por base empírica os PEEs relativos ao PNE 2014-2024, que tenham sido efetivamente transformados em norma jurídica - ou seja, aprovados pelo legislativo, sancionados pelo executivo e, ainda, publicados em órgão oficial do estado correspondente -, isto até o mês de dezembro de 2016.

Trata-se de um estudo de caráter exploratório e descritivo (KETELE; ROEGIERS, 1993), que se pauta na análise de conteúdo de documentos legislativos atinentes aos PEEs, método que visa favorecer a descoberta de "conteúdos e estruturas das mensagens e esclarecer elementos de significações de mecanismos não imediatamente perceptíveis"(BARDIN, 2004, p. 29). A um só tempo, levando em consideração o conjunto de elementos teóricoempíricos que se apresentem expressivos para as questões que norteiam a investigação, a análise dos dados também é possibilitada pelo emprego de aparelho estatístico habitual(LEVIN, 1987), com os cálculos de frequências simples e relativas sobre algumas das categorias temáticas, subcategorias e indicadores que sustentam o trabalho.

Assim, os PEEs foram analisados por meio de três categorias temáticas centrais relativas aos CMEs, a saber, "condições de funcionamento", "competências" e "organização interna". A primeira categoria, "condições de funcionamento", foi definida por meio de quatro subcategorias: constituição/fortalecimento, formação de conselheiros, infra-estrutura e autonomia, sendo que a subcategoria infra-estrutura veio a ser desagregada, para análise específica, em seis descritores (recursos financeiros, espaço físico, equipamentos, transporte, recursos humanos e manutenção). 
Do ponto de vista de sua organização, além desta introdução, o artigo possui outras três seções básicas. Na próxima seção (segunda) é traçado um panorama acerca dos PEEs alvo das análises realizadas, também indicando os marcos jurídicos que os regulamentam, sendo seguida pela análise relativa, na terceira seção, às condições de funcionamento dos CMEs e, na quarta seção, às competências e à organização interna desses mesmos órgãos. Na conclusão estabelecem-se as relações finais do estudo, de modo a permitir a visualização da forma pela qual os CMEs são considerados pelo planejamento estadual da educação em questão.

\section{A INSTITUCIONALIZAÇÃO DOS NOVOS PLANOS ESTADUAIS DE EDUCAÇÃO}

Até fins de dezembro de 2016, apenas 2 (8\%) dos 26 estados brasileiros não possuíam PEEs transformados em norma jurídica, ou seja, ainda não dispunham de planos que tivessem sido aprovados pelo legislativo, sancionados pelo executivo e, ainda, publicados em órgão oficial do estado correspondente,ambos da Região Sudeste, a saber, Minas Gerais e Rio de Janeiro. De acordo com dados constantes da página do Ministério da Educação (MEC) $)^{6}$, o estado de Minas Gerais ainda se encontrava com o seu plano em trâmite na Assembleia Legislativa, enquanto que o Rio de Janeiro possuía, unicamente, o documento base do plano elaborado ${ }^{7}$.

No que concerne ao conjunto de PEEs transformados em norma jurídica, cujo enquadramento legal encontra-se indicado no Quadro 1, sobressai um primeiro grupo de 3 (12\%) estados, composto pelo Maranhão, Mato Grosso e Mato Grosso do Sul, que veio a ter os seus respectivos PEEs aprovados em curto espaço de tempo em relação à promulgação do PNE 2014-2024, os dois primeiros, inclusive, alguns dias antes da aprovação deste plano nacional, que ocorreu em 25 junho de 2014, enquanto que o terceiro, seis meses após. No caso dos dois primeiros PEEs, tal aspecto põe em dúvida a sua elaboração, no

\footnotetext{
${ }^{6}$ Disponível em: <http://pne.mec.gov.br/planos-de-educacao/situacao-dos-planos-de-educacao>. Acesso em: 29 dez. 2016.

7 Cabe ainda destacar que o plano do estado do Mato Grosso possui apenas 17 metas publicadas no seu Diário Oficial (DO) (MATO GROSSO, 2014), expondo, em consequência, desalinhamento em relação a este novo plano nacional. Já os PEEs do Amazonas e Rondônia vieram a ter as suas leis publicadas nos respectivos DOs, mas desacompanhadas do texto do plano, cuja edição eletrônica é possível de se encontrar como documento avulso, apenas apensado à versão eletrônica do órgão oficial do estado (AMAZONAS, 2015; RONDÔNIA, 2015)
} 
sentido de terem resultado de discussões e deliberações pautadas no texto efetivamente aprovado deste novo PNE, envolvendo "ampla participação de representantes da comunidade educacional e da sociedade civil", conforme determinado no $\S 2^{\circ}$ da Lei $n^{\circ} 13.005 / 2014$ (BRASIL, 2014). Além disto, sugerem portar desalinhamentos também em relação a este novo PNE, na medida em que podem não ter contemplado, em efetivo, o conteúdo de suas metas e estratégias, tendo tomado por referência algumas das versões que transitaram no Congresso Nacional. Por exemplo, no PEE do Maranhão (2014) é explicitado que as "metas e estratégias estabelecidas estão em consonância com as do Plano Nacional de Educação (2010-2020) num regime de colaboração mútua [...]", numa clara referência não ao PNE 2014-2024 (BRASIL, 2014) aprovado, mas, possivelmente, a alguma versão preliminar deste plano nacional, derivada do Projeto de Lei (PL) $\mathrm{n}^{\circ}$ 8.035, de 20 de dezembro de 2010 (BRASIL, 2011).

\section{Quadro 1}

\section{Enquadramento legal dos PEEs alinhados ao PNE 2014-2024}

\begin{tabular}{|c|c|c|}
\hline REFERÊNCIA PEE & $\mathrm{N}^{0}$ da LEI e DATA DE APROVAÇÃO & $\begin{array}{l}\text { PERIOODO DE } \\
\text { VIGÊNCIA }\end{array}$ \\
\hline Acre (2015) & Lei n².965, de 2 de julho de 2015 & 2015-2024 \\
\hline Alagoas (2016) & Lei $n^{0} 7.795$, de 22 de janeiro de 2016 & $\left.2016-2026^{*}\right)$ \\
\hline Amapá (2015) & Lei $n^{0} 1.907$, de 24 de junho de 2015 & $2015-2025$ \\
\hline Amazonas (2015) & Lei $n^{0} 4.183$, de 26 de junho de 2015 & $\left.2015-2025^{*}\right)$ \\
\hline Bahia (2016) & Lei $n^{0} 13.559$, de 11 de maio de 2016 & $2016-2026\left(^{*}\right)$ \\
\hline Ceará (2016) & Lei $n^{0} 16.025$, de 30 de maio de 2016 & $2016-2024$ \\
\hline Espírito Santo (2015) & Lei $n^{0} 10.382$, de 24 de junho de 2015 & $2015-2025$ \\
\hline Goiás (2015) & Lei $n^{0} 18.969$, de 22 de julho de 2015 & $2015-2025$ \\
\hline Maranhão (2014) & Lei $n^{0} 10.099$, de 11 de junho de 2014 & $2014-\left(^{(* *)}\right.$ \\
\hline Mato Grosso (2014) & Lei $n^{0} 10.111$, de 06 de junho de 2014 & 2014- $\left(^{* \star}\right)$ \\
\hline Mato Grosso do Sul (2014) & $\begin{array}{r}\text { Lei n } 4.621 \text {, de } 22 \text { de dezembro de } \\
2014\end{array}$ & $2014-2024^{(*)}$ \\
\hline Minas Gerais & $\begin{array}{ll}+- \\
\end{array}$ & --- \\
\hline Pará (2015) & Lei $n^{0} 8.186$, de 23 de junho de 2015 & $2015-2025^{(*)}$ \\
\hline Paraíba (2015) & Lei $n^{0} 10.488$, de 23 de junho de 2015 & $\left.2015-20255^{*}\right)$ \\
\hline Paraná (2015) & Lei no 9.479, de 24 de junho de 2015 & $2015-2025$ \\
\hline Pernambuco (2015) & Lei $n^{0} 15.533$, de 23 de junho de 2015 & $2015-2025^{(*)}$ \\
\hline Piauí (2015) & $\begin{array}{r}\text { Lei } n^{0} 6.733 \text {, de } 17 \text { de dezembro de } \\
2015\end{array}$ & $2015-2025^{(*)}$ \\
\hline Rio de Janeiro & $\begin{array}{ll}+- \\
\end{array}$ & --- \\
\hline Rio Grande do Norte (2016) & Lei $n^{0} 10.049$, de 27 de janeiro de 2016 & $2015-2025$ \\
\hline
\end{tabular}




\begin{tabular}{|c|c|c|}
\hline Rio Grande do Sul (2015) & Lei no 14.705 , de 25 de junho de 2015 & $2015-2025\left(^{(*)}\right.$ \\
\hline Rondônia (2015) & Lei $n^{0} 3.565$, de 3 de junho de 2015 & $2014-2024$ \\
\hline Roraima (2015) & Lei $n^{0} 1.008$, de 3 de setembro de 2015 & $2014-2024$ \\
\hline Santa Catarina (2015) & $\begin{array}{r}\text { Lei no } 16.794 \text {, de } 14 \text { de dezembro de } \\
2015\end{array}$ & 2015-2024 \\
\hline São Paulo (2016) & Lei $n^{0} 16.279$, de 8 de julho de 2016 & $2016-2026\left(^{*}\right)$ \\
\hline Sergipe (2015) & $\begin{array}{r}\text { Lei no } 8.025 \text {, de } 04 \text { de setembro de } \\
2015\end{array}$ & $2015-2025^{(*)}$ \\
\hline Tocantins (2015) & Lei $n^{0} 2.977$, de 8 de julho de 2015 & $2015-2025$ \\
\hline
\end{tabular}

Um segundo agrupamento de 9 (38\%) estados - Amapá, Amazonas, Espírito Santo, Pará, Paraíba, Paraná, Pernambuco, Rio Grande do Sul e Rondônia - veio a ter os seus planos transformados em norma jurídica ao final do mês de junho de 2015, notadamente dentro do prazo previsto na Lei $\mathrm{n}^{\circ}$ $13005 / 2014$, qual seja, de um ano contado a partir de sua publicação (BRASIL, 2014, art. $8^{\circ}$ ). Ainda em 2015, destaca-se outro conjunto de 7 (29\%) estados, composto pelos PEEs do Acre, Goiás e Tocantins, com menos de um mês de atraso; de Roraima e Sergipe, com quase três meses; enquanto que Santa Catarina e Piauí expondo, aproximadamente, seis meses de demora.

Os demais $5(21 \%)$ estados vieram a ter os seus planos transformados em norma jurídica apenas a partir do início de 2016, a saber, Alagoas, Rio Grande do Norte, Bahia, Ceará e São Paulo, os dois primeiros com atraso de sete meses, os dois seguintes com 11 meses, enquanto que o quinto estado com mais de um ano de retardo relativo ao prazo legal, denotando desalinhamentos temporais expressivos em relação àquele novo plano nacional.

\section{AS CONDIÇÕES DE FUNCIONAMENTO DOS CMEs NO ÂMBITO DOS PEES}

$\mathrm{Na}$ área da educação, em particular no âmbito da Educação Básica, e em meio aos desafios postos - inicialmente pela Constituição Federal (CF) de 1988 (BRASIL, 1988) e, oito anos após, pela Lei de Diretrizes e Bases da Educação Nacional (LDBEN) n ${ }^{\circ}$ 9.394, de 20 de dezembro de 1996 (BRASIL, 1996) - à implantação da Gestão Democrática no País, disseminam-se os CEs, os Conselhos de Classe e de Série, os Grêmios Estudantis, os Conselhos de Acompanhamento e Controle Social (CACS) e, especialmente, os CMEs (SOUZA, 2013a; 2008; 2006; MARTINS, 2011; SCHEINVAR; ALGEBAILE, 2005). 
Neste contexto, os municípios, uma vez elevados à condição de entes federados, passaram a possuir a incumbência, entre outras, de "organizar, manter e desenvolver os órgãos e instituições oficiais dos seus sistemas de ensino, integrando-os às políticas e planos educacionais da União e dos Estados" (BRASIL, 1996, art. 11, I) ou, no caso de não optarem pela constituição dos seus próprios sistemas, integrarem-se "ao sistema estadual de ensino ou compor com ele um sistema único de educação básica" (BRASIL, 1996, art. 11, parágrafo único).

A primeira modalidade, considerada por Cury $(2004$, p. 20) como "a base de um sistema municipal de ensino, próprio e autônomo", refere-se à criação propriamente dita de um Sistema Municipal de Ensino próprio, abrangendo: i) as instituições escolares de Educação Básica - de Educação Infantil, de Ensino Fundamental e de Ensino Médio (caso haja) públicas e, ainda, privadas de Educação Infantil; ii) os órgãos de administração central da educação municipal - a Secretaria Municipal de Educação (SME), instância predominantemente executiva, que exerce funções de coordenação, supervisão, articulação e implementação das políticas e ações educacionais, e o CME, de caráter preponderantemente normativo, mas também com outras funções mais adiante discutidas (SOUZA, DUARTE; OLIVEIRA, 2013); assim como o iii) PME e o conjunto de normas complementares emanadas por estes órgãos (SARI; MARTINS; CASTIGLIONI, 2006).

Já a opção de integração ao Sistema Estadual de Ensino implica considerar que, ao invés de o CME vir a exercer sua função normativa, esta competência passa a ser prerrogativa do CEE. Por seu turno, a composição com o Sistema Estadual de Ensino de um Sistema Único de Educação Básica remete à condição de que a administração das instituições públicas de ensino seja realizada conjuntamente pelo estado e município (SARI; MARTINS; CASTIGLIONI, 2006).

Ainda de acordo com Sari, Martins e Castiglioni (2006, p. 93), "a maioria dos municípios brasileiros encontra-se em uma situação que poderia ser ainda considerada de transição entre o regime anterior (Lei $n^{0} 5.692 / 71$ ) e as possibilidades previstas na atual legislação", isto pelo fato de não terem constituído os seus próprios Sistemas Municipais de Ensino e, em consequência, ainda encontrarem-se normativamente vinculados ao Sistema Estadual de Ensino, não significando, contudo, existência da integração aludida pela LDBEN nº 9.394/1996 (BRASIL, 1996). 
Todavia, mesmo nos casos em que o município possua o seu próprio Sistema Municipal de Ensino,alguns estudos vêm constatando a debilidade da autonomia local dos CMEs. Conforme aventado na introdução deste artigo, o balanço sobre a produção científica relacionada ao funcionamento institucional e sociopolítico desses órgãos, realizado por Souza, Duarte e Oliveira (2013), indica que não apenas a consolidação da Gestão Democrática vem sendo comprometida, como, a um só tempo, o exercício da autonomia, isto, entre outros aspectos, em decorrência de diversas formas de ingerência do Poder Executivo no seu funcionamento. Nestes termos, a participação do conselho como construtor da política educacional fica comprometida, apresentando um trabalho frágil, legitimando a política vigente, estando muito aquém das suas potencialidades (CALDERON, 2008). Tais Conselhos acabam, portanto, por legitimar decisões tomadas pelo alto, também com vistas ao recebimento de eventuais recursos, o que implica considerar a existência de órgãos meramente formais e com um papel caracteristicamente coadjuvante (CARNIELLI; GOMES, 2008).Assim, parece haver desafios de distintas ordens para a efetivação de uma Gestão Democrática local - nesses e por esses órgãos -, de cunho participativo, "como a persistência de uma cultura patrimonialista que trata a coisa pública como algo privado, além de uma política elitista que naturaliza o protagonismo de poucos" (SOUZA; ALCÂNTARA, 2016, p. 197).

Do ponto de vista do planejamento nacional da educação, sabe-se que o PNE 2014-2024 (BRASIL, 2014) menciona os Conselhos de Educação13 vezes em seu texto, das quais apenas $1(8 \%)$ se refere, explicitamente, aos CMEs propriamente ditos. A maioria das referências, 4 (31\%), alude ao Conselho Nacional de Educação (CNE) e,3 (23\%) delas aos CEs. Os CACS são mencionados $2(15 \%)$ vezes e os Conselhos de Alimentação Escolar (CAEs), Conselhos Regionais e demais Conselhos de Acompanhamento de Políticas Públicas são indicados1(8\%) vez cada um.

A Meta 19 deste novo PNE, que se refere à Gestão Democrática, concentra mais da metade das referências aos Conselhos, 7 (54\%), embora nenhuma delas se refira ao $\mathrm{CNE}^{8}$ que, apesar de mais presente que os demais Conselhos no texto, ficou fora da meta relativa à Gestão Democrática da

8 O CNE foi mencionado no PNE 2014-2024 (BRASIL, 2014) no artigo relativo ao seu monitoramento e avaliação (Art. $5^{\circ}$, III); na meta que dispõe sobre a universalização do Ensino Fundamental (Meta 2, Estratégia 1) e do Ensino Médio (Meta 3, Estratégia 1); e naquela que estabelece o investimento público e educação (Meta 20, Estratégia 8). 
educação. Essa meta dispõe, quanto à Gestão Democrática, que a mesma deverá ser assegurada, em um prazo de dois anos da vigência do Plano, "associada a critérios técnicos de mérito e desempenho e à consulta pública à comunidade escolar, no âmbito das escolas públicas, prevendo recursos e apoio técnico da União para tanto"(BRASIL, 2014, Meta 19). Quanto aos CMEs, conforme sinalizado na introdução deste artigo, o documento estabelece, na Estratégia 5 da Meta 20, que a sua "constituição e fortalecimento" deverão ser estimulados, também incluindo os CEs, "como instrumentos de participação e fiscalização na gestão escolar e educacional, inclusive por meio de programas de formação de conselheiros, assegurando-se condições de funcionamento autônomo" (BRASIL, 2014, Meta 20, Estratégia $5)$.

Além dessa referência direta, os CMEs também podem ser incluídos, embora de modo genérico e inespecífico, na referência feita pelo PNE 20142024 aos Conselhos de Acompanhamento de Políticas Públicas, cuja íntegra é a seguinte:

\begin{abstract}
ampliar os programas de apoio e formação aos (às) conselheiros (as) dos conselhos de acompanhamento e controle social do Fundeb, dos conselhos de alimentação escolar, dos conselhos regionais e de outros e aos (às) representantes educacionais em demais conselhos de acompanhamento de politicas públicas, garantindo a esses colegiados recursos financeiros, espaço físico adequado, equipamentos e meios de transporte para visitas à rede escolar, com vistas ao bom desempenho de suas funções[grifos nossos] (BRASIL, 2014, Meta 19, Estratégia 2).
\end{abstract}

O dispositivo acima merece destaque, em se tratando de CMEs, já que, juntamente com a Estratégia 5 da mesma Meta 19, conforme acima, influenciaram fortemente os PEEs, não só quanto ao conteúdo e diretrizes políticas gerais explícitos nesses documentos, mas, inclusive, quanto ao texto propriamente dito, tendo alguns planos reproduzido literalmente as estratégias mencionadas.

Todos os 24 PEEs analisados comprometem os governos estaduais - e, alguns, sob a perspectiva do regime de colaboração, também os municipais -, com as condições de funcionamentos dos CMEs. Assim, a constituição e o fortalecimento dos CMEs foram mencionados em todos dos documentos estudados, seja por meio de ações diretas ou de estímulo à ação dos governos municipais. Apoiando a constituição e o fortalecimento dos CMEs, 14 (58\%) dos PEEs destacam que a garantia de sua infra-estrutura ocorra por meio de: 
recursos financeiros, 10 (42\%); de espaço físico, 11 (46\%); de equipamentos, 9 (37\%); de transporte 9 (37\%); de recursos humanos, 4 (17\%) e/ou por intermédio de materiais para manutenção, $3(12 \%)$.

Se a maioria dos PEEs, no que se refere à infra-estrutura, reproduz o texto da Estratégia 2 da Meta 19 do novo PNE, conforme citado acima, merece destaque o PEE do Rio Grande do Sul (2015), cuja referência aos CMEs está em 11 dispositivos específicos e que, em seu texto, ao dispor sobre a infraestrutura, estabelece, dentre outros aspectos, a garantia do

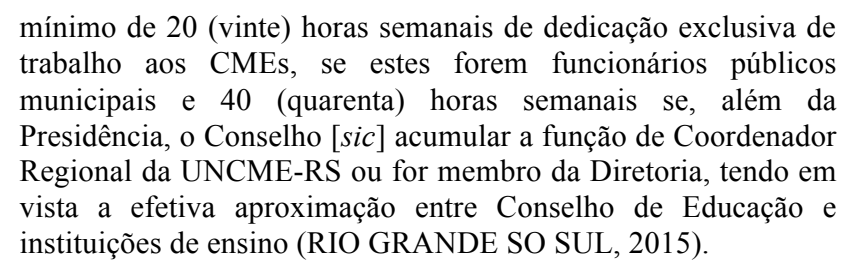

Além da infra-estrutura, os PEEs, repercutindo o PNE 2014-2024 (BRASIL, 2014), mencionam a autonomia dos CMEs, relacionando-a às suas condições de funcionamento. Dos PEEs estudados, 14 (58\%) fazem referência a esse aspecto, sendo que, daqueles que reportam à garantia de infra-estrutura para os CMEs, 8 (57\%) mencionam a autonomia desse órgão. Contudo, no que se refere às condições de funcionamento, o aporte de maior recorrência nos PEEs, abaixo da sua constituição e fortalecimento, é a formação de conselheiros. Essa ação dos governos estaduais e/ou municipais está presente em $19(79 \%)$ dos documentos analisados e comumente associada ao texto relativo à criação e ao fortalecimento dos CMEs, tal como dispõe a Estratégia 5 da Meta 20 do novo plano nacional (BRASIL, 2014).

Assim, em termos de adesão aos dispositivos do PNE 2014-2024 (BRASIL, 2014), pode-se afirmar que os PEEs analisados, quando mencionam as condições de funcionamento dos CMEs,fazem-no por meio de normas literalmente relacionadas ao documento nacional, em maior ou menor proporção. Há, porém, uma ordem decrescente de adesão aos elementos previstos neste novo plano nacional quando o mesmo se refere aos CMEs no âmbito da Gestão Democrática da educação. A constituição e o fortalecimento dos CMEs são os elementos de maior adesão dos PEEs aos dispositivos do PNE 2014-2024 (BRASIL, 2014), já que todos os PEEs dispuseram sobre esse aspecto. A formação de conselheiros repercutiu em quase $80 \%$ dos PEEs analisados, conforme mostrado acima, apresentando-se esse elemento como o 
segundo de maior aderência dos planos estaduais em relação ao nacional. A autonomia e a infra-estrutura foram mencionadas, cada uma, em mais da metade dos documentos analisados, em terceira posição quanto à relação mencionada.

Assim, ao que parece, os CMEs, em decorrência do que estabelece o planejamento nacional (BRASIL, 2014), obtiveram significativo aporte normativo nos PEEs aqui enfocados, seja para a sua criação (naqueles municípios onde possivelmente ainda não tenha ocorrido), seja para o seu fortalecimento, por meio principalmente da previsão de formação dos seus conselheiros, mas também por intermédio de infra-estrutura, cuja finalidade sugere convergir para o assegurar da autonomização desse órgão e, a um só tempo, para o exercício de competências e organização específicas,aspectos abordados a seguir.

\section{AS COMPETÊNCIAS E A ORGANIZAÇÃO INTERNA DOS CMES NO ÂMBITO DOS PEES}

Conforme visto na seção anterior, a maior parcela dos municípios brasileiros não possui os seus próprios Sistemas Municipais de Ensino, encontrando-se, ainda, normativamente vinculados aos Sistemas Estaduais de Ensino (SARI; MARTINS; CASTIGLIONI, 2006). De fato, segundo a Pesquisa de Informações Básicas Municipais (MUNIC), realizada pelo Instituto Brasileiro de Estatística (IBGE), relativa ao ano de 2011 (BRASIL, IBGE, 2012), apenas 2.048 (36,8\%) municípios, de um total, à época, de 5.565 , possuíam sistema de ensino próprios, estando o restante $(63,2 \%)$ vinculado aos respectivos sistemas estaduais.

Dentre o conjunto de órgãos que compõem esses sistemas de ensino, a mesma pesquisa do IBGE informa que os CMEs se fazem notar em cerca de $4.718(84,8 \%)$ do total de localidades do país, constituindo-se num órgão majoritariamente paritário quanto as representações do poder público e da sociedade civil (BRASIL, IBGE, 2012). Entretanto, conforme salientam Souza \& Vasconcelos (2012, p. 53) "tal repartição, na prática, significa apenas um possível equilíbrio numérico de forças colegiadas, não devendo ser tomada como garantia da prevalência ou hegemonia de interesses sociais mais amplos sobre os privados $[\ldots] "$. 
Ao longo da história do funcionamento dos Conselhos de Educação no Brasil ${ }^{9}$, as competências precipuamente desempenhadas por esses órgãos junto ao MEC ou às Secretarias Estaduais de Educação (SEEs) foram, caracteristicamente, a normativa, a deliberativa, a consultiva e a de assessoramento, moduladas por um perfil tipicamente técnico-pedagógico (BORDIGNON, 2009; BRASIL, MEC, SEB, 2008; 2007a).

De modo geral, a função normativa implica definição de normas para o sistema de ensino, limitadamente à sua abrangência ou jurisdição; a deliberativa exprime-se pela competência em decidir sobre questões específicas em determinadas áreas e matérias de alçadado sistema (por exemplo, credenciamento de instituições e autorização de cursos) e a função consultiva volta-se para o atendimento de consultas apresentadas tanto pelo Poder Público - por exemplo, casas legislativas, Ministério Público (MP), Secretaria de Educação-, neste caso, também configurando função de assessoramento, quanto pela sociedade civil - por exemplo, escolas, universidades, sindicatos ou qualquer cidadão ou grupo (BORDIGNON, 2009; BRASIL, MEC, SEB, 2008; 2007a).

Após a promulgação da CF/1988 (BRASIL, 1988), acrescentam-se ao conjunto das funções anteriormente sinalizadas a propositiva, mobilizadora, fiscalizadora e de controle social, agora como competências, por característica, a serem localmente exercidas pelos CMEs. Essas funções vieram a despontar, portanto, concomitantemente à criação dos Sistemas Municipais de Ensino e, em particular, dos CMEs, no contexto da elevação dos municípios à condição de entes autônomos federados, assumindo, aos poucos, importância no funcionamento desses Conselhos locais, isto de modo coeso aos princípios da democracia participativa. Neste novo cenário, a função propositiva passa a atribuir ao CME caráter não apenas reativo (como ocorre no cumprimento da função consultiva), mas de protagonista na formulação de propostas, sugestões e, de forma ampla, de políticas locais de educação no âmbito do sistema municipal, enquanto que a mobilizadora se inclina para as ações de estímulo aos processos participativos da sociedade no acompanhamento e controle dos serviços locais da educação, aglutinando esforços emanados pelo poder público (BORDIGNON, 2009; BRASIL, MEC, SEB, 2007b).

Já as funções fiscalizadora e de controle social remetem ao acompanhamento propriamente dito da execução das políticas públicas locais

${ }^{9}$ Veja-se, entre outros, Bordignon (2009; 2001), Cury (2001), Boaventura (1992) e Werle(1998). 
de educação, assim como à averiguação do cumprimento da legislação em vigência, diferenciando-se em termos "da aplicação de sanções às instituições ou pessoas físicas que descumprem a lei ou as normas" (BRASIL, MEC, SEB, $2007 b$, p. 18). No primeiro caso, o CME, no exercício das ações de fiscalização, poderá aplicar sanções previstas em lei, por exemplo, suspendendo matrículas ou cessando o funcionamento de cursos regulares. Quando no cumprimento da função de controle, uma vez "constatada irregularidade ou descumprimento da legislação pelo poder público, [o] conselho poderá pronunciar-se, solicitando esclarecimento dos responsáveis, ou denunciando aos órgãos fiscalizadores" - Câmara de Vereadores, Tribunais de Conta (TCs) ou MPs (BRASIL, MEC, SEB, 2007b, p. 19). Com a aprovação da Lei $\mathrm{n}^{\circ} 11.494$, de 20 de junho de 2007, que regulamentou o Fundo de Manutenção e Desenvolvimento da Educação Básica e de Valorização dos Profissionais da Educação (FUNDEB), as ações de controle do CME passaram a poder englobar o "acompanhamento e o controle social sobre a distribuição, a transferência e a aplicação dos recursos do Fundo" (BRASIL, 2007, art. 37), isto por meio da constituição de Câmara específica que venha a integrar o CACS desse Fundo e em observância às formas de organização e de representação fixadas nesta lei.

Do conjunto de funções exercidas por estes órgãos, excluindo-se a mobilizadora e a propositiva, o estudo do IBGE anteriormente mencionado destaca que, ainda em relação à totalidade dos municípios do país, à época (5.565), que $4.008(72 \%)$ declararam que exercem a consultiva, $3.966(71 \%)$ a deliberativa, $3.186(57 \%)$ a normativa e, por fim, $3.735(67 \%)$ a fiscalizadora, denotando certa equidade no exercício das competências basais desses órgãos (BRASIL, IBGE, 2012).

Dispositivo sobre as competências dos CMEs no âmbito dos Sistemas Municipais de Ensino consta no PNE 2014-2024 (BRASIL, 2014), na Estratégia 5 da Meta 19, mencionada na seção anterior. Trata-se da definição dos CMEs como "instrumentos de participação e fiscalização na gestão escolar e educacional" (BRASIL, 2014), fazendo-se presente em metade dos PEEs analisados. Participar e fiscalizar a gestão escolar e educacional é função associada no PNE 2014-2024 (BRASIL, 2014) à própria constituição e fortalecimento dos CMEs. Tal associação, reproduzida da norma nacional em $50 \%$ dos PEEs estudados, precede, nesses documentos, um conjunto de funções tradicionalmente atribuídas a esses órgãos, tais como a deliberativa, consultiva e mobilizadora. Juntas, ou em parte, estas funções foram mencionadas em 7 (29\%) dos 24 PEEs analisados, enquanto participar e 
fiscalizar a gestão escolar e educacional, como dito, foi referido pela metade dos documentos pesquisados.

Há, além das funções anteriormente aludidas, 7 (29\%) PEEs que definem atribuições específicas para os CMEs, que vão desde ações locais, circunscritas ao âmbito dos Sistemas Municipais de Ensino, a outras de escopo estadual, articuladas aos Sistemas Estaduais e, em alguns casos, especificamente aos CEEs.

Destacam-se, no âmbito dos PEEs em foco, entre as atribuições específicas dos CMEs no domínio dos sistemas municipais de ensino, referências à ações tais como: elaborar diretrizes e normas para a educação infantil; acompanhar a expansão e avaliar a educação infantil;elaborar normas sobre a organização do trabalho pedagógico; elaborar indicadores para avaliação da educação especial; normatizar a ampliação do tempo de permanência dos estudantes na escola;estabelecer parcerias com outros órgãos para o pleno atendimento da educação básica; coordenar as conferências municipais de educação;fiscalizar as políticas de acessibilidade plena e de inclusão no ensino regular; e, ainda, exercer controle social.

No plano estadual, as competências atribuídas aos CMEs pelos PEEs são variadas, tais como: regulamentar, juntamente com os CEEs, as normas, os procedimentos e os prazos para definição de mecanismos de consulta pública sobre a demanda das famílias por creches e por pré-escola; acompanhar e avaliar a execução dos PEEs e dos PMEs; fiscalizar a aplicação adequada dos recursos do salário-educação; supervisionar e fiscalizar, juntamente com outros órgãos, a formação de professores e o funcionamento da educação escolar indígena e quilombola; colaborar, juntamente com o CEE, no acompanhamento do funcionamento legal das escolas localizadas no campo, nas terras indígenas e quilombolas.

Por fim, $4(17 \%)$ entre os 24 PEEs analisados dispõem sobre a organização interna dos CMEs, todos eles se referindo à mecanismos potencialmente garantidores do caráter democráticos desses órgãos. Tais planos, em síntese, abordam a constituição dos CMEs articulada à representação de diferentes segmentos da sociedade civil, com ampla representação social e composto de forma paritária, como órgãos plurais, coerentemente com a meta relativa à gestão democrática da educação. 


\section{CONCLUSÕES}

Retrospectivamente, a análise dos PEEs, por meio da categoria "condições de funcionamento" dos CMEs, mostrou que há uma intensa repercussão nesses documentos da responsabilização atribuída pelo PNE 20142024 (BRASIL, 2014) aos poderes executivos estaduais e municipais não só pelo funcionamento desses órgãos colegiados, mas em termos de sua autonomização, isto por meio da garantia, sobretudo, de infra-estrutura e de formação de conselheiros. Pode-se especular a respeito da extensão dos efeitos dessa responsabilização legal aludindo à fraca incorporação da dinâmica local, nos casos da simples reprodução do texto nacional nos textos dos PEEs. Porém, merece atenção, em contexto de discussão sobre a constituição de um Sistema Nacional de Educação (SNE) e suas implicações para a reconfiguração dos Sistemas Municipais e Estaduais de Ensino, o fato de que os CMEs permaneçam acolhidos e protegidos no âmbito das políticas de planejamento estaduais, inclusive na sua articulação com o planejamento nacional e municipal, por meio do comprometimento de ações efetivas dos governos estaduais.

A atribuição de competências aos CMEs, no âmbito do planejamento estadual, também se mostrou uma evidência forte na análise dos PEEs, uma vez que define os próprios CMEs como instrumentos de participação e fiscalização na gestão escolar e educacional.Tal atribuição pode ser controversa, na medida em que se situa no limite tênue da autonomia intrínseca à natureza dos sistemas de ensino e, principalmente, se associada aos dispositivos nos PEEs que estabelecem critérios para a própria organização interna dos CMEs. Embora não seja objetivo deste artigo debater esse tema na sua amplitude teórico-conceitual, parece importante notá-locomo uma tensão presente nos PEEs que, se por um lado, revela um escopo de atuação dos CMEs que ultrapassa o âmbito local, relacionando-o às políticas estaduais, por outro lado, contrasta com os dispositivos de autonomia, tanto dos sistemas de ensino, quanto dos próprios CMEs no âmbito dos respectivos sistemas.

De todas as formas, se considerados alguns dos resultados de investigações congêneres sobre os Conselhos de Educação nos Planos de Educação, conforme indicado na introdução deste artigo, se observa que, se por um lado, os PEEs transparecem reconhecer a importância dos CMEs na gestão democrática da educação local, quer em virtude da repercussão das determinações constantes do PNE 2014-2024, quer em decorrência de sua própria perspectiva política, por outro lado, parecem desconsiderar o valor do seu próprio Conselho, o CEE, como órgão estratégico dos Sistemas Estaduais 
de Ensino, isto com referência ao identificado na pesquisa de Oliveira, Souza \& Câmara (2016) sobre esses mesmos planos. Tal contradição pode ser explicada tanto pela possibilidade de os CMEs estarem sendo reconhecidos como legítimos herdeiros de algumas das competências e práticas dos CEEs em âmbito local, destacadamente em relação à normatização da educação municipal, como também pela influência exercida na legislação estadual pelas normas nacionais que, como destacamos, afirmam a responsabilidade dos entes subnacionais em relação ao CMEs, mas silencia quanto aos CEEs

\section{REFERÊNCIAS}

ACRE (Estado). Lei no 2.965, de 2 de julho de 2015. Aprova o Plano Estadual de Educação para o decênio 2015-2024 e dá outras providências. Diário Oficial [do] Estado de Acre, Rio Branco, 03 jul. 2015.

ALAGOAS (Estado). Lei $\mathrm{n}^{\circ} 7.795$, de 22 de janeiro de 2016. Aprova o Plano estadual de Educação PEE, e dá outras providências. Diário Oficial [do] Estado de Alagoas, Maceió, 25 jan. 2016.

AMAPÁ (Estado). Lei no 1.907, de 24 de junho de 2015. Dispõe sobre o Plano Estadual de Educação - PEE, para o decênio 2015 -2025, e dá outras providências. Diário Oficial [do] Estado do Amapá, Macapá, 24 de junho de 2015.

AMAZONAS (Estado). Lei n ${ }^{\circ} 4.183$, de 26 de junho de 2015. Aprova o Plano Estadual de Educação do Estado do Amazonas e dá outras providências. Diário Oficial [do] Estado do Amazonas, Manaus, 26 jun. 2015.

BAHIA (Estado). Lei $\mathrm{n}^{\circ} 13.559$, de 11 de maio de 2016. Aprova o Plano Estadual de Educação da Bahia e dá outras providências. Diário Oficial [do] Estado da Bahia, Salvador, 12 maio 2016.

BARDIN, Laurence. Análise de conteúdo. 4. ed. Lisboa: Edições 70, 2004.

BOAVENTURA, Edivaldo Machado. Criação e reorganização do Conselho de Educação da Bahia. Revista Sitientibus, Feira de Santana, n. 10, p. 13-30, jul./dez. 1992.

BORDIGNON, Genuíno. Gestão da educação no município: sistema, conselho e plano. São Paulo: Instituto Paulo Freire, 2009. 
- Natureza dos conselhos de educação. João Pessoa: Secretaria de Educação e Cultura, 2001.

BRASIL Projeto de Lei do Plano Nacional de Educação (PNE 2011-2020): Projeto em tramitação no Congresso Nacional - PL n ${ }^{0} 8.035 / 2010$. Brasília, DF: Câmara dos Deputados, Edições Câmara, 2011.

Constituição [de 1988] da República Federativa do Brasil. Diário Oficial da União [da] República Federativa do Brasil, Brasília, DF, 5 out. 1988.

Instituto Brasileiro de Geografia e Estatística. Diretoria de Pesquisas. Coordenação de População e Indicadores Sociais. Perfil dos municípios brasileiros 2011. Rio de Janeiro: IBGE, 2012.

Lei $\mathrm{n}^{\circ}$ 10.172, de 09 de janeiro de 2001. Aprova o Plano Nacional de Educação (PNE). Diário Oficial da União [da] República Federativa do Brasil, Brasília, DF, 10 jan. 2001.

Lei $\mathrm{n}^{\circ} 11.494$, de 20 de junho de 2007. Regulamenta o Fundo de Manutenção e Desenvolvimento da Educação Básica e de Valorização dos Profissionais da Educação - FUNDEB, de que trata o art. 60 do Ato das Disposições Constitucionais Transitórias; altera a Lei no 10.195 , de 14 de fevereiro de 2001; revoga dispositivos das Leis $\mathrm{n}^{\circ} 9.424$, de 24 de dezembro de 1996, 10.880, de 9 de junho de 2004, e 10.845, de 5 de março de 2004; e dá outras providências. Diário Oficial [da] República Federativa do Brasil, Brasília, DF, 21 jun. 2007.

Lei $\mathrm{n}^{\circ}$ 13.005, de 25 de junho de 2014. Aprova o Plano Nacional de Educação - PNE e dá outras providências. Diário Oficial da União [da] República Federativa do Brasil, Brasília, DF, 26 jun. 2014.

Lei $\mathrm{n}^{\circ}$ 9.394, de 20 de dezembro de 1996. Estabelece as Diretrizes e

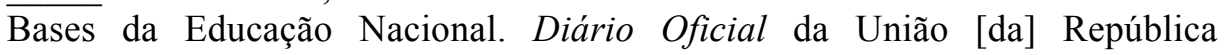
Federativa do Brasil, Brasília, DF, 23 dez. 1996.

Ministério da Educação. Secretaria de Educação Básica. Programa Nacional de Capacitação de Conselheiros Municipais de Educação - PróConselho:guia de consulta. Brasília, DF: MEC, SEB, 2007a. 
- Ministério da Educação. Secretaria de Educação Básica. Programa

Nacional de Capacitação de Conselheiros Municipais de Educação: perfil dos Conselhos Municipais de Educação 2006. Brasília, DF: MEC, SEB, 2007 b.

- Ministério da Educação. Secretaria de Educação Básica. Programa Nacional de Capacitação de Conselheiros Municipais de Educação: perfil dos Conselhos Municipais de Educação 2007. Brasília, DF: MEC, SEB, 2008.

CALDERÓN, Adolfo Ignacio. Conselhos municipais: representação, cooptação e modernização da política patrimonialista. In: SOUZA, Donaldo Bello de (Org.). Conselhos municipais e controle social da educação: descentralização, participação e cidadania. São Paulo: Xamã, 2008, p. 169189.

CARNIELLI, Beatrice Laura; GOMES, Candido Alberto. Os Cacs e as raízes sociopolíticas brasileira. In: SOUZA, Donaldo Bello de (Org.). Conselhos municipais e controle social da educação: descentralização, participação e cidadania. São Paulo: Xamã, 2008, p. 133-151.

CEARÁ (Estado). Lei ${ }^{\circ} 16.025,30$ de maio de 2016. Dispõe sobre o plano estadual de educação (2016/2024). Diário Oficial [do] Estado do Ceará, Fortaleza, v. 8, n. 101, 30 maio 2016.

CURY, Carlos Roberto Jamil. O regime de colaboração no ordenamento jurídico da educação escolar brasileira. In: BRASIL. Ministério da Educação. Secretaria de Educação Básica. Programa Nacional de Capacitação de Conselheiros Municipais de Educação Pró-Conselho: caderno de referência. Brasília, DF: MEC/SEB, 2004, p. 10-23.

Os Conselhos Estaduais de Educação nas Constituições Estaduais

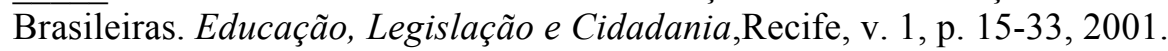

ESPÍRITO SANTO (Estado). Lei n ${ }^{\circ} 10.382$, de 24 de junho de 2015. Aprova o Plano estadual de Educação do espírito Santo - PEE/ES, período 2015/2025. Diário Oficial [do] Estado do Espírito Santo, Vitória, 25 jun. 2015.

GOIÁS (Estado). Lei $\mathrm{n}^{\circ} 18.969$, de 22 de julho de 2015. Aprova o Plano Estadual de Educação para o decênio 2015/2025 e dá outras providências. Diário Oficial [do] Estado de Goiás, Goiânia, 27 jul. 2015. 
KETELE, Jean-Marie de; ROEGIERS, Xavier. Metodologia da recolha de dados: fundamentos dos métodos de observações, de questionários, de entrevistas e de estudo de documentos. Lisboa: Instituto Piaget, 1993.

LEVIN, Jack. Estatística aplicada a ciências humanas. 2. ed. São Paulo: Harbra, 1987.

MARANHÃO (Estado). Lei $\mathrm{n}^{\circ}$ 10.099, de 11 de junho de 2014. Aprova o Plano Estadual de Educação do Estado do Maranhão e dá outras providências. Diário Oficial [do] Estado do Maranhão, São Luiz, 11 jun. 2014.

MARTINS, Ângela Maria (Org.). Estado da Arte: gestão, autonomia escolar e órgãos colegiados (2000/2008). Brasília: Liber; Niterói: Anpae, 2011.

MATO GROSSO (Estado). Lei $\mathrm{n}^{\circ} 10.111$, de 06 de junho de 2014. Dispõe sobre a revisão e alteração do Plano Estadual de Educação, instituído pela Lei $\mathrm{n}^{\circ}$ 8.806, de 10 de janeiro de 2008. Diário Oficial [do] Estado do Mato Grosso, Cuiabá, 06 jun. 2014.

MATO GROSSO DO SUL (Estado). Lei $\mathrm{n}^{\circ} 4.621$, de 22 de dezembro de 2014. Aprova o Plano Estadual de Educação de Mato Grosso do Sul, e dá outras providências. Diário Oficial [do] Estado do Mato Grosso do Sul, Campo Grande, 26 dez. 2014.

OLIVEIRA, Dalila Andrade de. Das políticas de governo à política de estado: reflexões sobre a atual agenda educacional brasileira. Educação \& Sociedade, Campinas, v. 32, n. 115, p. 323-337, abr./jun. 2011.

OLIVEIRA, Rosimar de Fátima; SOUZA, Donaldo Bello de; CÂMARA, Adriane Peixoto. Conselhos Estaduais de Educação nos novos Planos Estaduais de Educação. Rio de Janeiro: Nephem/FE/Uerj; Belo Horizonte: Pase/Faced/UFMG (digitado), 2016.

PARÁ (Estado). Lei $\mathrm{n}^{\circ}$ 8.186, de 23 de junho de 2015. Aprova o Plano Estadual de Educação - PEE e dá outras providências. Diário Oficial [do] Estado do Pará, Belém, 24 jun. 2015.

PARAÍBA (Estado). Lei no 10.488, de 23 de junho de 2015. Aprova o Plano Estadual de Educação - PEE e dá outras providências. Diário Oficial [do] Estado da Paraíba, João Pessoa, Suplemento, 24 jun. 2015. 
PARANÁ (Estado). Lei no 18.492, de 24 de Junho de 2015. Aprovação do Plano Estadual de Educação e adoção de outras providências. Diário Oficial [do] Estado do Paraná, Curitiba, 25 jun. 2015.

PERNAMBUCO (Estado). Lei $\mathrm{n}^{\circ} 15.533$, de 23 de junho de 2015. Aprova o Plano Estadual de Educação PEE. Diário Oficial [do] Estado de Pernambuco, Recife, 24 jun. 2015.

PIAUÍ (Estado). Lei no 6.733, de 17 de dezembro de 2015. Diário Oficial [do] Estado do Piauí, Teresina, 21 dez. 2015.

RIO GRANDE DO NORTE (Estado). Lei n ${ }^{\circ}$ 10.049, de 27 de janeiro de 2016. Aprova o Plano Estadual de Educação do Rio Grande do Norte (2015-2025) e dá outras providências. Diário Oficial[do] Estado do Rio Grande do Norte, Natal, 27 jan. 2016.

RIO GRANDE DO SUL (Estado). Lei $\mathrm{n}^{\circ}$ 14.705, de 25 de junho de 2015. Institui o Plano Estadual de Educação - PEE -, em cumprimento ao Plano Nacional de Educação - PNE -, aprovado pela Lei Federal n ${ }^{0} 13.005$, de 25 de junho de 2014. Diário Oficial [do] Estado do Rio Grande do Sul, Porto Alegre, 26 jun. 2015.

RONDÔNIA (Estado). Lei $n^{0} 3.565$, de 3 de junho de 2015. Institui o Plano Estadual de Educação de Rondônia. Diário Oficial [do] Estado de Rondônia, Porto Velho, 3 de junho de 2015.

RORAIMA (Estado). Lei $\mathrm{n}^{\mathrm{o}} 1.008$, de 3 de setembro de 2015. Aprova o Plano Estadual de Educação 2014-2024 (PEE) e dá outras providências. Diário Oficial [do] Estado de Roraima, Boa Vista, 3 de setembro de 2015.

SANTA CATARINA (Estado). Lei $\mathrm{n}^{\circ}$ 16.794, de 14 de dezembro de 2015. Aprova o Plano Estadual de Educação (PEE) para o decênio 2015-2024 e estabelece outras providências. Diário Oficial [do] Estado de Santa Catarina, Florianópolis, 15 de dezembro de 2015.

SÃO PAULO (Estado). Lei $\mathrm{n}^{\circ} 16.279$, de 8 de julho de 2016. Aprova o Plano Estadual de Educação de São Paulo e dá outras providências. Diário Oficial [do] Estado de São Paulo, São Paulo, 09 jul. 2016.

SARI, Marisa Timm; MARTINS, Ricardo Chaves de Rezende; CASTIGLIONI, Vera Lúcia Baptista. Organização da educação nacional no contexto do fortalecimento da Educação Básica: o papel do município. In: 
BRASIL. Ministério da Educação. Secretaria de Educação Básica. Pradime: Programa de Apoio aos Dirigentes Municipais de Educa. Brasília, DF, MEC/SEB, 2006, p. 79-130 (Caderno de Textos, 1).

SCHEINVAR, Estela; ALGEBAILE, Eveline. (Orgs.). Conselhos participativos e escola. Rio de Janeiro: DP\&A, 2005.

SERGIPE (Estado). Lei $\mathrm{n}^{\circ}$ 8.025, de 04 de setembro de 2015. Dispõe sobre o Plano Estadual de Educação - PEE, e dá providências correlatas. Diário Oficial [do] Estado de Sergipe, Aracajú, 08 set. 2015.

SOUZA, Donaldo Bello de (Org.). Acompanhamento e controle social da educação: fundos e programas federais e seus conselhos locais. São Paulo: Xamã, 2006.

- (Org.). Conselhos municipais e controle social da educação: descentralização, participação e cidadania. São Paulo: Xamã, 2008.

. (Org.). Mapa dos Conselhos Municipais de Educação no Brasil. São Paulo: Loyola, 2013a.

Apresentação. In: (Org.). Mapa dos Conselhos Municipais de Educação no Brasil. São Paulo: Loyola, 2013b, p. 11-17.

O papel dos Conselhos de Acompanhamento e Controle Social nos Planos Estaduais de Educação alinhados ao PNE 2014-2024. Revista HISTEDBR On-line, Campinas, n. 68, p. 182-207, jun. 2016.

SOUZA, Donaldo Bello de; ALCÂNTARA, Alzira Batalha. O lugar dos Conselhos Municipais de Educação nos PMEs relativos ao PNE 2001-2010. Revista Educação em Questão, Natal, v. 54, p. 191-219, 2016.

SOUZA, Donaldo Bello de; DUARTE, Marisa Ribeiro Teixeira; OLIVEIRA, Rosimar de Fátima. CMEs no Brasil: uma cartografia a partir dos estudos teórico-empíricos. In: SOUZA, Donaldo Bello de (Org.). Mapa dos Conselhos Municipais de Educação no Brasil. São Paulo: Loyola, 2013, p. 23-55.

SOUZA, Donaldo Bello de; MENEZES , Janaína Specht da Silva. Elaboração e aprovação de planos de educação no Brasil: do nacional ao local. Ensaio: Avaliação e Políticas Públicas em Educação, Rio de Janeiro, v. 23, n. 89, p. 901-936, 2015. 
SOUZA, Donaldo Bello de; VASCONCELOS, Maria Celi Chaves. CMEs no estado do Rio de Janeiro: considerações sobre o funcionamento institucional e sociopolítico a partir de 28 de suas localidades. In: VALLE, Bertha de Borja Reis do; VASCONCELOS, Maria Celi Chaves (Orgs.). Conselhos municipais de educação: organização e atribuições nos sistemas de ensino do estado do Rio de Janeiro. Rio de Janeiro: Quartet; Faperj, 2012, p. 27-54.

TOCANTINS (Estado). Lei $\mathrm{n}^{\circ} 2.977$, de 8 de julho de 2015. Aprova o Plano Estadual de Educação do Tocantins - PEE/TO (2015-2025), e adota outras providências. Diário Oficial [do] Estado do Tocantins, Palmas, 9 jul. 2015.

WERLE, Flávia Obino Corrêa. Conselhos Municipais de Educação: estudo genético-histórico. Cadernos de Pesquisa, São Paulo, nº 103, p. 123-135, mar. 1998.

Recebido em 31/10/2016

Aprovado em 29/03/2017 